\title{
Biosynthesis of anthracyclines: carminomycin 4- $O$-methyltransferase, the terminal enzymic step in the formation of daunomycin
}

\author{
Neal C. Connors, Paul L. Bartel $\dagger$ and William R. Strohl* \\ Department of Microbiology, The Ohio State University, 484 West 12th Avenue, Columbus, Ohio 43210, USA
}

(Received 3 January 1990; revised 11 May 1990; accepted 13 June 1990)

\begin{abstract}
In the presence of $S$-adenosyl-L-methionine, cell-free extracts of Streptomyces sp. C5, Streptomyces peucetius ATCC 29050, Streptomyces insignis ATCC 31913 and Streptomyces coeruleorubidus ATCC 31276 O-methylated carminomycin and 13-dihydrocarminomycin to daunomycin and 13-dihydrodaunomycin, respectively. With the corresponding aglycones, carminomycinone and 13-dihydrocarminomycinone, as substrates, no methylated products were detected. Other 4-hydroxyanthracyclines such as aklavin and aclacinomycin $\mathbf{A}$, and 4-hydroxyanthracyclinones such as $\varepsilon$-rhodomycinone and aklavinone, were not substrates for the 4- $O$-methyltransferase. These reaction specificities indicate that glycosylation of the anthracyclinone molecule must occur before 4-O-methylation, which means that 4-O-methylation of carminomycin is probably the terminal step in the biosynthesis of daunomycin, and that daunomycinone is not an intermediate in the pathway.
\end{abstract}

\section{Introduction}

Although daunomycin (DiMarco et al., 1964), adriamycin (Arcamone et al., 1969), carminomycin (Brazhnikova et al., 1974) and related anthracyclines (Fujiwara \& Hoshino, 1983; Strohl et al., 1989; Fig. 1) are important anti-tumour drugs, the biosynthetic pathways for their formation have not been well elucidated (Strohl et al., 1989). Several biosynthetic pathways have been postulated for the biosynthesis of daunomycin (Blumauerová et al., 1979 b; Eckardt \& Wagner, 1988; Fujiwara \& Hoshino, 1983; Yoshimoto et al., 1980) but these are based on in vivo bioconversions and intermediates accumulated by a limited number of mutants. Recent studies by Eckardt and his colleagues (reviewed by Eckardt \& Wagner, 1988), confirmed by our in vitro analyses (see accompanying paper: Connors et al., 1990), have helped to elucidate the sequence of the early steps in daunomycin biosynthesis. On the other hand, the enzymic reactions converting $\varepsilon$-rhodomycinone to daunomycin still remain largely uncharacterized (Strohl et al., 1989). A better understanding of the daunomycin biosynthesis pathway will assist investigation of the genetics of daunomycin biosynthesis and will also assist in the rational design of experiments to generate hybrid

† Present address: Department of Microbiology, State University of New York at Stony Brook, Stony Brook, NY 11794, USA.

Abbreviations: SAM, $S$-adenosyl-L-methionine. anthracycline antibiotics via interspecies cloning of anthracycline biosynthesis genes. We describe the $S$ adenosyl-L-methionine(SAM)-dependent methylation of carminomycin and 13-dihydrocarminomycin to daunomycin and 13-dihydrodaunomycin (see Fig. 1 for structures), respectively, by several daunomycin-producing strains.

\section{Methods}

Streptomyces sp. strain $\mathrm{C} 5$, which produces $\varepsilon$-rhodomycinone and baumycins (anthracyclines related to daunomycin; McGuire et al., 1980), was obtained from the Frederick Cancer Research Center. Streptomyces galilaeus (ATCC 31133), which produces aclacinomycin A (Oki et al., 1979), and the daunomycin producing strains Streptomyces peucetius (ATCC 29050), Streptomyces coeruleorubidus (ATCC 31276) and Streptomyces insignis (ATCC 31913; Tunac et al., 1985) were obtained from the American Type Culture Collection.

The growth of these streptomycetes and preparation of desalted cell extracts are described by Connors et al. (1990). To determine which anthracyclinone and anthracycline substrates were methylated by cell extracts of anthracycline-producing streptomycetes, assays contained, $0.25 \mathrm{ml}$ : anthracycline or anthracyclinone substrate, 5 to $10 \mu \mathrm{g} ; S$ adenosyl-[methyl $\left.{ }^{-14} \mathrm{C}\right]-\mathrm{L}-$ methionine ([methyl-14 C]SAM) (New England Nuclear), $2 \cdot 15 \mathrm{nmol}$ (46 Ci mol${ }^{-1} ; 1.7 \mathrm{TBq} \mathrm{mol}^{-1}$ ); cell extract, $0.2 \mathrm{ml}\left(1-2 \mathrm{mg}\right.$ protein $\mathrm{ml}^{-1}$; prepared in $100 \mathrm{~mm}-\mathrm{K}_{2} \mathrm{HPO}_{4} / \mathrm{KH}_{2} \mathrm{PO}_{4}$ buffer, $\mathrm{pH} 7.5$ ). The volume was adjusted to $0.25 \mathrm{ml}$ with $100 \mathrm{~mm}$ phosphate buffer $(\mathrm{pH} 7 \cdot 5)$. The reaction mixture was incubated at $37^{\circ} \mathrm{C}$ for $60 \mathrm{~min}$, after which the products were extracted into 3 vols of chloroform/methanol $(9: 1, \mathrm{v} / \mathrm{v})$. The extracted material was air-dried, and then redissolved in $10 \mu$ lof chloroform (plus authentic standard for cochromatography) for application to a $0.25 \mathrm{~mm}$ layer of silica gel. The 


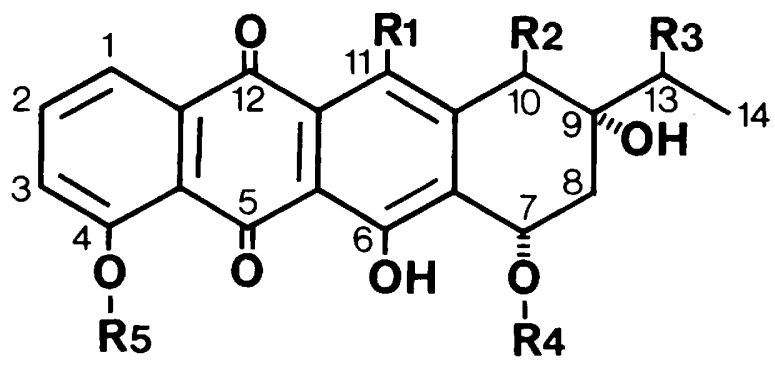

\begin{tabular}{llllll}
\hline \hline \multicolumn{1}{c}{ Compound* } & $\mathrm{R} 1$ & $\mathrm{R} 2$ & $\mathrm{R} 3$ & $\mathrm{R} 4 \dagger$ & $\mathrm{R} 5$ \\
\hline Daunomycin (P) & $-\mathrm{OH}$ & $-\mathrm{H}$ & $=\mathrm{O}$ & $-\mathrm{DN}$ & $-\mathrm{CH}_{3}$ \\
13-Dihydrodaunomycin (P) & $-\mathrm{OH}$ & $-\mathrm{H}$ & $-\mathrm{OH}$ & $-\mathrm{DN}$ & $-\mathrm{CH}_{3}$ \\
Carminomycin (S) & $-\mathrm{OH}$ & $-\mathrm{H}$ & $-\mathrm{O}$ & $-\mathrm{DN}$ & $-\mathrm{H}$ \\
13-Dihydrocarminomycin (S) & $-\mathrm{OH}$ & $-\mathrm{H}$ & $-\mathrm{OH}$ & $-\mathrm{DN}$ & $-\mathrm{H}$ \\
Aclacinomycin A (S) & $-\mathrm{H}$ & $-\mathrm{COOCH}_{3}$ & $-\mathrm{H}$ & $-\mathrm{RN}-\mathrm{dF}-\mathrm{LC}$ & $-\mathrm{H}$ \\
Aklavin (S) & $-\mathrm{H}$ & $-\mathrm{COOCH}_{3}$ & $-\mathrm{H}$ & $-\mathrm{RN}$ & $-\mathrm{H}$ \\
Carminomycinone (S) & $-\mathrm{OH}$ & $-\mathrm{H}$ & $=\mathrm{O}$ & $-\mathrm{H}$ & $-\mathrm{H}$ \\
13-Dihydrocarminomycinone (S) & $-\mathrm{OH}$ & $-\mathrm{H}$ & $-\mathrm{OH}$ & $-\mathrm{H}$ & $-\mathrm{H}$ \\
$\varepsilon$-Rhodomycinone (S) & $-\mathrm{OH}$ & $-\mathrm{COOCH}_{3}$ & $-\mathrm{H}$ & $-\mathrm{H}$ & $-\mathrm{H}$ \\
Aklavinone (S) & $-\mathrm{H}$ & $-\mathrm{COOCH}_{3}$ & $-\mathrm{H}$ & $-\mathrm{H}$ & $-\mathrm{H}$ \\
\hline \hline
\end{tabular}

* Letters in parentheses indicate: $\mathrm{P}$, product of methyltransferase reaction; $\mathrm{S}$, substrate for methyltransferase reaction.

† Sugars: DN, daunosamine; RN, rhodosamine; dF, 2-deoxy-L-fucose; LC, L-cinerulose A.

Fig. 1. Structures of the anthracyclines and anthracyclinones discussed in this paper.

thin-layer chromatography (TLC) plates (Whatman) were developed with either chloroform/heptane/methanol $(5: 5: 1$, by vol.; SS1) for anthracyclinone products, or chloroform/methanol/glacial acetic acid $/ \mathrm{H}_{2} \mathrm{O}(15: 5: 1: 1$, by vol.; $\mathrm{SS} 2)$ for anthracycline products. The developed chromatograms containing radioactive products were then exposed to X-ray film (Kodak X-Omat AR) for 3 to $5 \mathrm{~d}$. Reaction products were compared to authentic standards by cochromatography or chromatography in parallel. Aglycones of the methylated products were prepared by hydrolysing the radioactive anthracyclines with $0.1 \mathrm{M}-\mathrm{HCl}$ for $60 \mathrm{~min}$ at $90^{\circ} \mathrm{C}$. The aglycone hydrolysis products were extracted into chloroform/methanol ( $9: 1)$, air-dried, and reconstituted in $10 \mu \mathrm{l}$ chloroform for TLC as above. Radioactive aglycones were separated using SSI and the chromatograms were viewed under UV light and autoradiographed.

\section{Results and Discussion}

Using [methyl $\left.-{ }^{14} \mathrm{C}\right] \mathrm{SAM}$ as the methyl donor, desalted cell extracts of Streptomyces sp. C5 methylated carminomycin and 13-dihydrocarminomycin to $\left[{ }^{14} \mathrm{C}\right]$ daunomycin and $13-\left[{ }^{14} \mathrm{C}\right]$ dihydrodaunomycin, respectively (Fig. $2 a, b)$. None of the other 4-hydroxyanthracyclines (aklavin, aclacinomycin A) or 4-hydroxyanthracyclinones (aklavinone, $\varepsilon$-rhodomycinone, carminomycinone, 13-dihydrocarminomycinone) tested were suitable substrates for the 4-O-methyltransferase reaction (data not shown). The two methylation products were identified by cochromatography with authentic standards in TLC solvent system SS2 (Fig. 2b). Moreover, the radiolabelled methylation products were hydrolysed to their aglycones, and these (daunomycinone and 13-dihydrodaunomycinone) were separated and identified by TLC using SS1 (Fig. $2 c$ ). Since the reactions gave daunomycin, daunomycinone and their 13-hydroxy derivatives rather than unknown products, the methylation took place at the 4- $O$-position as expected.

Desalted cell extracts or other daunomycin-producing strains tested, i.e. $S$. peucetius, $S$. insignis and $S$. coeruleorubidus, also methylated carminomycin and 13dihydrocarminomycin to $\left[{ }^{14} \mathrm{C}\right]$ daunomycin and 13$\left[{ }^{14} \mathrm{C}\right]$ dihydrodaunomycin, respectively (data not shown). Aklavin, aclacinomycin A, aklavinone, $\varepsilon$-rhodomycinone, carminomycinone and 13-dihydrocarminomycinone were not substrates for the 4-O-methyltransferases of these strains, as also observed with Streptomyces sp. C5. This suggests that late enzymic reactions in the daunomycin biosynthesis pathways of the different strains that produce daunomycin are highly conserved. We found similar conservation in early reactions of the daunomycin pathway (Connors et al., 1990). On the other hand, cell extracts of $S$. galilaeus 31133 , which produces aclacinomycin A (Oki et al., 1979), did not methylate any of the substrates tested (data not shown). This is consistent with the lack of a $4-O$-methyl group in 


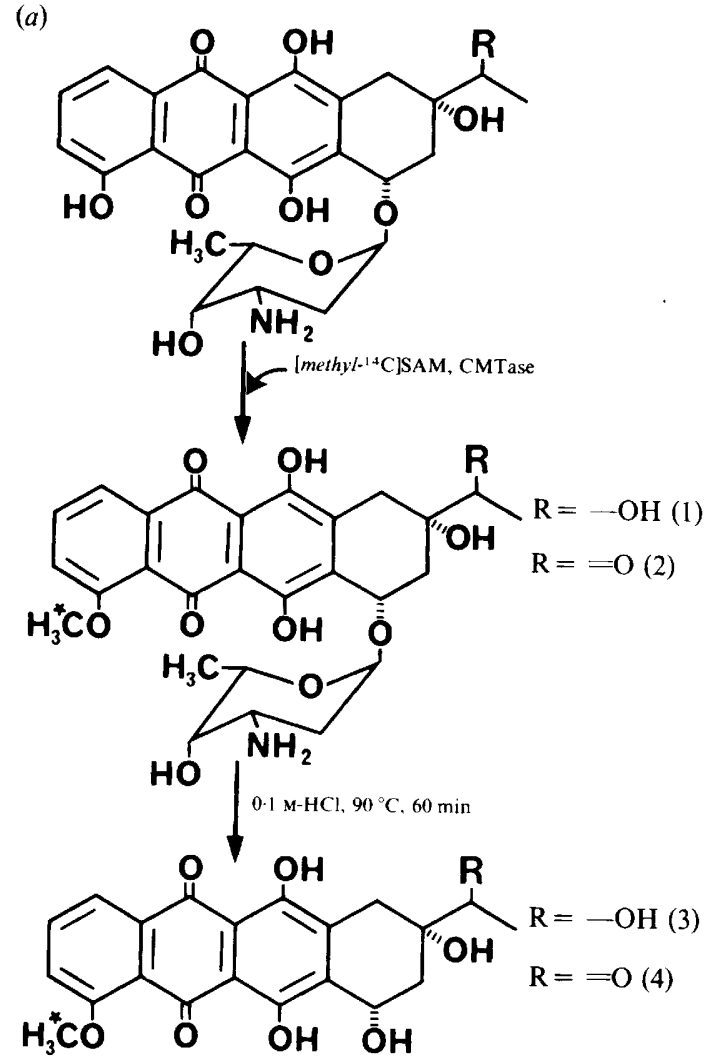

(b)



(c)

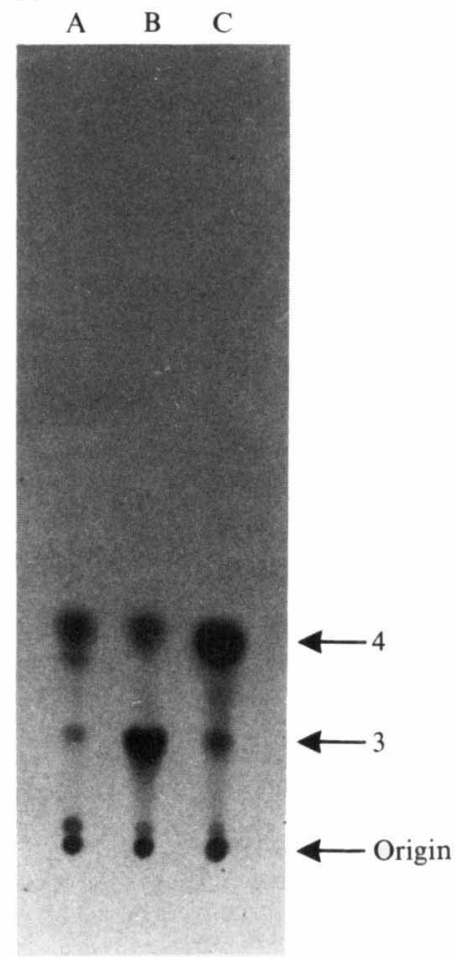

aclacinomycin $\mathrm{A}$ as well as other products of this strain (Strohl et al., 1989; Fig. 1).

The enzymic reactions leading to the formation of $\varepsilon$-rhodomycinone, an important intermediate in the biosynthesis of daunomycin (McGuire et al., 1980; Strohl et al., 1989), have recently been clarified (Eckardt \& Wagner, 1988; Connors et al., 1990). On the other hand, the biosynthetic steps required to convert $\varepsilon$-rhodomycinone to daunomycin are virtually uncharacterized, although it is obvious that the following reactions must take place: (i) decarbomethoxylation at C-10; (ii) twostep oxidation from a methylene to a keto group at $\mathrm{C}-13$; (iii) $O$-methylation of the $\mathrm{C}-4$ hydroxyl group; and (iv) glycosylation with daunosamine of the C-7 hydroxyl group (Strohl et al., 1989). This study provides the first information about the order of these reactions. Since the 4-O-methyltransferases of every daunomycin-producing strain tested required glycosides as substrates, glycosylation must take place before $4-O$-methylation. Similarly, since aklavin and aclacinomycin A were not substrates for the 4-O-methyltransferases, it is possible that compounds containing 10-carbomethoxyl groups cannot be methylated (Fig. 1). $\varepsilon$-Rhodomycinone contains the carbomethoxyl group at C-10 (Fig. 1), suggesting that decarbomethoxylation must take place before 4-Omethylation. On the other hand, since aklavin and aclacinomycin $A$ have sugars other than daunosamine attached at C-7 (Fig. 1), the reaction specificity may lie in the sugar residue and not in the absence of the carbomethoxyl group.

Both 13-dihydrocarminomycin and carminomycin were good substrates for the 4-O-methyltransferase, so the oxidation state of $\mathrm{C}-13$ apparently is of little consequence to the 4-O-methyltransferase in vitro. It is not clear from our results which of these is the preferred substrate in vivo. However, 13-dihydrodaunomycin has been shown to be a product of daunomycin metabolism, and not an intermediate in daunomycin biosynthesis (Crespi-Perellino et al., 1982). Since the product of the

Fig. 2. (a) Methylation of 13-dihydrocarminomycin $(\mathrm{R}=-\mathrm{OH})$ and carminomycin $(\mathrm{R}=\mathrm{O})$ to 13-dihydrodaunomycin (1) and daunomycin (2), respectively, with subsequent acid hydrolysis to 13-dihydrodaunomycinone (3) and daunomycinone (4), respectively. (b) Autoradiogram of products after separation by TLC using SS2; the products were formed by methylation of 13-dihydrocarminomycin and carminomycin with [methyl $\left.{ }^{-14} \mathrm{C}\right] \mathrm{SAM}$ and cell extracts of Streptomyces C5. Lanes: A, No substrate added (background control); B 13-dihydrocarminomycin added as substrate; major radioactive products are 13dihydrodaunomycin (1) and 13-dihydrodaunomycinone (3); C, carminomycin added as substrate; major radioactive products are daunomycin (2) and daunomycinone (4). (c) Autoradiogram of products after separation by TLC using SS1; the products were from acid hydrolysis of compounds shown in (b). Lanes: A, No substrate added (background control); B, hydrolysis of 13-dihydrodaunomycin yielded 13-dihydrodaunomycinone (3) as the major product; hydrolysis of daunomycin yielded daunomycinone (4) as the major product. 
4-O-methylation of 13-dihydrocarminomycin is 13-dihydrodaunomycin, which was shown not to be a precursor to daunomycin (Crespi-Perellino et al., 1982), this would rule out 13-dihydrocarminomycin as a substrate for the 4$O$-methyltransferase in vivo. Thus, combining our data and those of Crespi-Perellino et al. (1982), the pathway for biosynthesis of 13-dihydrodaunomycin from 13dihydrocarminomycin would most probably be: 13dihydrocarminomycin $\rightarrow$ carminomycin $\rightarrow$ daunomycin $\rightarrow$ 13-dihydrodaunomycin. In support of this pathway is the finding that daunomycin can be reduced to 13-dihydrodaunomycin by a wide variety of micro-organisms (Marshall, 1985), suggesting that 13-dihydrodaunomycin is a degradation product rather than a biosynthetic intermediate.

Our data indicate that organisms accumulating the anti-tumour drug carminomycin (Brazhnikova et al., 1974) may differ from daunomycin-producing strains simply by lacking $4-O$-methyltransferase activity. This is supported by the finding that addition of DL-ethionine, an inhibitor of methylation, to a daunomycin-producing culture of $S$. coeruleorubidus caused the culture to accumulate carminomycin (Blumauerová et al., 1979a). This would place the carminomycin 4-O-methyltransferase reaction at the last step in daunomycin biosynthesis.

Whether daunomycinone, the aglycone equivalent of daunomycin, is a precursor to daunomycin has been disputed for some time (Blumauerová et al., 1979b, $c$; Fujiwara \& Hoshino, 1983; Yoshimoto et al., 1980). Because our data indicate that glycosylation must take place before 4-O-methylation, daunomycinone cannot be a precursor. In the in vitro reactions in which 13dihydrocarminomycin and carminomycin were methylated to 13-dihydrodaunomycin and daunomycin, respectively, the corresponding aglycones (13-dihydrodaunomycinone and daunomycinone) were usually obtained as minor products (Fig. $2 b$ ). Thus, the cell extracts were able to hydrolyse the glycosides to the respective aglycones, further indicating that daunomycinone and 13-dihydrodaunomycinone are degradation products rather than biosynthetic intermediates. Similarly, Yoshimoto et al. (1980) demonstrated that carminomycinone but not daunomycinone could be converted in vivo to baumycins and daunomycin by a blocked mutant of $S$. coeruleorubidus ME130-A4. On the other hand, Blumauerová et al. $(1979 c)$ showed that mutants of $S$. coeruleorubidus JA10092 could apparently glycosylate exogenously added daunomycinone. Their data would suggest that $S$. coeruleorubidus JA10092 may utilize a different pathway in the formation of daunomycin, or, on the other hand, the daunomycinone used as a substrate in the in vivo conversion studies by Blumauerová et al. (1979c) may have been converted to a different aglycone before conversion to daunomycin.
We sincerely thank J. Lunel of Rhône-Poulenc for authentic samples of carminomycinone and 13-dihydrocarminomycinone. We also thank Adria and the Frederick Cancer Research Center for authentic anthracycline and anthracyclinone samples.

This work was supported by the National Science Foundation under no. DMB-8607619.

\section{References}

Arcamone, F., Cassinelli, G., Fantini, G., Grein, A., Orezzi, P., Pol, C. \& Spalla, C. (1969). Adriamycin, 14-hydroxydaunomycin, a new antitumour antibiotic from $S$. peucetius var. caesius. Biotechnology and Bioengineering 11, 1101-1110.

Blumauerová, M., Jizba, J., Stajner, K. \& VanĚK, Z. (1979a). Effect of DL-ethionine on the biosynthesis of anthracyclines in Streptomyces coeruleorubidus. Biotechnology Letters 1, 471-476.

Blumauerová, M., Královcová, E., HošŤálek, Z. \& VaněK, Z. $(1979 \mathrm{~b})$. Intra- and interspecific cosynthetic activity of mutants of Streptomyces coeruleorubidus and Streptomyces galilaeus impaired in the biosynthesis of anthracyclines. Folia Microbiologica 24, 128-135. Blumauerov́a, M., Královcová, E., Matěứ, J., Jizba, J. \& VanĚK, Z. (1979c). Biotransformation of anthracyclinones in Streptomyces coeruleorubidus and Streptomyces galilaeus. Folia Microbiologica 24, $117-127$.

Brazhnikova, M. G., Abarsky, V. B., Ponomarenko, V. I. \& Potapova, N. P. (1974). Physical and chemical characteristics and structure of carminomycin, a new antitumor antibiotic. Journal of Antibiotics 27, 254-259.

Connors, N. C., Bartel, P. L. \& Stroht, W. R. (1990). Biosynthesis of anthracyclines: enzymic conversion of aklanonic acid to aklavinone and $\varepsilon$-rhodomycinone by anthracycline-producing streptomycetes. Journal of General Microbiology 136, 1895-1898.

Crespi-Perellino, N., Grein, A., Merli, S., Minghetti, A. \& SPALla, C. (1982). Biosynthetic relationships among daunorubicin, doxorubicin and 13-dihydrodaunorubicin in Streptomyces peucetius. Experientia 38, 1455-1456.

DiMarco, A., Gaetani, M., Dorigotti, L., Soldati, M. \& Bellini, O. (1964). Daunomycin: a new antibiotic with antitumor activity. Cancer Chemotherapy Reports 38, 31-38.

ECKARDT, K. \& WAGNER, C. (1988). Biosynthesis of anthracyclinones. Journal of Basic Microbiology 28, 137-144.

Fujiwara, A. \& Hoshino, T. (1983). Anthracycline antibiotics. CRC Reviews in Biotechnology 3, 133-157.

MARShALl, V. P. (1985). Microbial transformation of anthracycline antibiotics and analogs. Developments in Industrial Microbiology 26, 129-142.

McGuire, J. C., Thomas, M. C., Stroshane, R. M., Hamilton, B. K. \& WHITE, R. J. (1980). Biosynthesis of daunorubicin glycosides: role of $\varepsilon$-rhodomycinone. Antimicrobial Agents and Chemotherapy 18, 454464.

OKI, T., Kitamura, I., Matsuzawa, Y., Shibamoto, N., Ogasawara, T., Yoshimoto, A. \& INUI, T. (1979). Antitumor anthracycline antibiotics, aclacinomycin A and analogs. Journal of Antibiotics 32, 801-819.

Strohl, W. R., Bartel, P. L., Connors, N. C., Zhu, C.-B., DosCh, D. C., Beale, J. M., Jr, Floss, H. G., Stutzman-Engwall, K., OTTEN, S. L. \& HutChinson, C. R. (1989). Biosynthesis of natural and hybrid polyketides by anthracycline producing streptomycetes. In Genetics and Molecular Biology of Industrial Microorganisms, pp. 68-84. Edited by C. L. Hershberger, S. W. Queener \& G. Hegeman. Washington, DC: American Society for Microbiology.

Tunac, J. B., Graham, B. D., Dobson, W. E. \& Lenzini, M. D. (1985), Fermentation by a new daunomycin-producing organism, Streptomyces insignis ATCC 31913. Applied and Environmental Microbiology 49, 265-268.

Yoshimoto, A., OKI, T., Takeuchi, T. \& Umezawa, H. (1980) Microbial conversion of anthracyclinones to daunomycin by blocked mutants of Streptomyces coeruleorubidus. Journal of Antibiotics 33, 1158-1166. 